\title{
Nitrogen Injection in Molten Aluminum in a Tank Degasser
}

\author{
Luis A. Maldonado, Miguel A. Barron, Dulce Y. Miranda \\ Departamento de Materiales, Universidad Autonoma Metropolitana Azcapotzalco, Ciudad de Mexico, Mexico \\ Email:bmma@correo.azc.uam.mx
}

How to cite this paper: Maldonado, L.A., Barron, M.A. and Miranda, D.Y. (2018) Nitrogen Injection in Molten Aluminum in a Tank Degasser. World Journal of Engineering and Technology, 6, 685-695. https://doi.org/10.4236/wjet.2018.64044

Received: August 13, 2018

Accepted: September 10, 2018

Published: September 13, 2018

Copyright ( $\odot 2018$ by authors and Scientific Research Publishing Inc. This work is licensed under the Creative Commons Attribution International License (CC BY 4.0).

http://creativecommons.org/licenses/by/4.0/

\begin{abstract}
The injection of nitrogen in molten aluminum through a static impeller in a tank degassing unit is studied. Using basic principles of fluid mechanics, it is analyzed the influence of the nozzle diameter on the bubble diameter and the mean residence time of the bubbles in the molten aluminum. By means of transient isothermal 2D Computational Fluid Dynamics (CFD) simulations, the influence of the nitrogen volumetric flow rate on the phase distributions and the tank degasser dynamics is studied. Finally, an adiabatic CFD simulation is carried out in order to elucidate the changes in the molten aluminum temperature due to the injection of nitrogen at ambient temperature. This simulation shows that molten aluminum does not suffer drastic temperature reductions given that, in spite that the nitrogen is fed at ambient temperature, the mass of nitrogen is relatively small compared with the mass of aluminum.
\end{abstract}

\section{Keywords}

Aluminum Degassing, Bubble Diameter, CFD Simulations, Molten

Aluminum, Nitrogen Injection, Residence Time, Tank Degasser

\section{Introduction}

Molten aluminum is very reactive chemically, and promptly reacts with water forming atomic hydrogen which is easily dissolved in it. Water comes from the atmospheric water vapor, wet refractory, wet raw materials, combustion products, and so on. Unfortunately, when molten aluminum is cast in semi-finished forms and solidifies, atomic hydrogen is no longer dissolved in solid aluminum and forms bubbles of molecular hydrogen which in its turn gives raise to small but harmful pores. Porosity is one of the worst defects in aluminum castings given that it causes a significant decrease of the mechanical properties and the corrosion resistance [1]. 
Many methods and technologies are employed at industry for degassing of molten aluminum. For example, gaseous and solid fluxes, which are blends of chloride and fluoride salts, may be used to remove dissolved hydrogen in aluminum and its alloys by chemical reaction [2] [3]. The removal of hydrogen from molten aluminum with vacuum is based on the equilibrium relationship between the dissolved hydrogen and the hydrogen partial pressure in ambient atmosphere [4] [5] [6]. Ultrasonic degassing of aluminum rests on the diffusion of dissolved hydrogen to cavitation bubbles assisted by their pulsation and their evacuation from the molten metal [7] [8] [9]. However, the worldwide most employed process for hydrogen removal from molten aluminum is the inert gas injection by rotating impeller (IGIRI). In this process an inert gas (argon or nitrogen) enters into the molten aluminum through a rotating impeller with several nozzles. The gas bubbles are generated by shear and collision with the vanes of the rotor [4].

The IGIRI process has been extensively analyzed by plant trials, physical modeling and computer simulations in order to elucidate the most important parameters and variables which determine the efficiency of hydrogen removal from molten aluminum. In [10] it is analyzed the influence of four major parameters (gas flow rate, rotational speed, refining time, and stewing time) on the degassing rate of an aluminum alloy with the IGIRI process by using an orthogonal experiment methodology. Authors report that the rotational speed has the greatest impact on degassing. Recently, the hydrodynamic performance of a stirred ladle for an aluminum degassing system was studied by means of water model experiments in [11]. The authors explore the dynamic flow features using diverse impellers with geometrical differences, and the performance is evaluated at two gas flow rates. The Particle Image Velocimetry (PIV) technique was applied to obtain the velocity fields during the degassing process. In [12] [13], numerical simulations with Computational Fluid Dynamics (CFD) software were used to simulate the fluid flow in a water physical model of a molten aluminum ladle with IGIRI process for degassing. The effect of critical process parameters such as rotor speed, gas flow rate, and the point of gas injection on the fluid flow and vortex formation were analyzed. The effect of the impeller design on degassing kinetics using the IGIRI process is studied too. The effect of the IGIRI degassing process variables on the casting quality of an aluminum alloy was investigated in [14]. The authors report that the effectiveness of the rotary degassing process is highly dependent on the combination of rotational speed and the gas flow rate, and that a wrong combination of these factors may result in no improvement or even degradation in the quality of castings.

In this work, the injection of nitrogen in molten aluminum through a submerged static impeller in a tank degassing unit is considered. The impeller has six nozzles located at its submerged end. Unlike the above works, here the bubble size, the mean residence time, the stirring power, and the mixing time are determined for the degasser tank. The influence of the nozzle diameter on the 
bubble diameter and the mean residence time of the bubbles in the molten aluminum were mathematically analyzed. Besides, using transient 2D Computational Fluid Dynamics (CFD) simulations, the influence of the nitrogen volumetric flow rate on the phase distributions, the system dynamics and the temperature distribution is studied.

\section{Degasser Description}

The considered tank degasser is depicted in Figure 1. It resembles a degasser commonly employed at industry nowadays. For the sake of simplicity, the impeller is here considered static, i.e. the impeller is not rotating. Parameters of the degasser and physical properties of the involved phases are shown in Table 1 and Table 2, respectively.

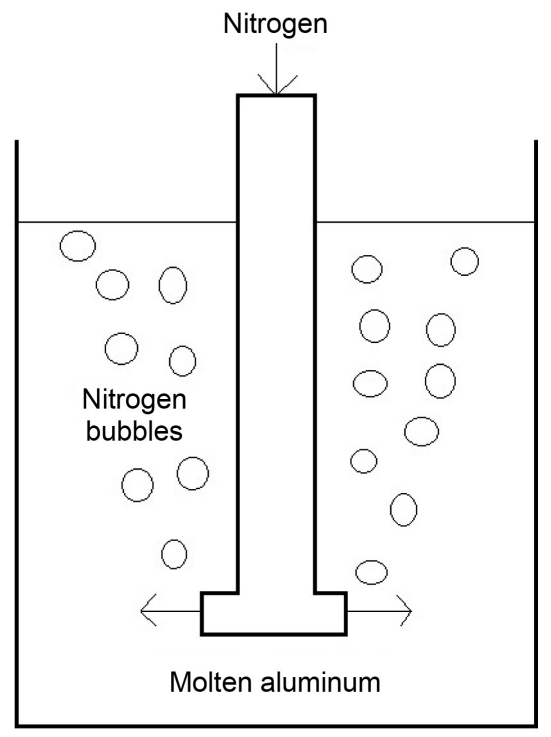

Figure 1. Tank degasser of molten aluminum with nitrogen injection through a static impeller.

Table 1. Parameters of the tank degasser.

\begin{tabular}{cc}
\hline PARAMETER & VALUE \\
\hline Molten aluminum volume & $0.43 \mathrm{~m}^{3}$ \\
Molten aluminum weight & $989 \mathrm{~kg}$ \\
Diameter & $0.937 \mathrm{~m}$ \\
Nitrogen flow rate & $1,1.50,2,3 \mathrm{~m}^{3} / \mathrm{h}$ \\
Pressure at the molten metal surface & $1 \mathrm{~atm}$ \\
Impeller immersion depth & $0.55 \mathrm{~m}$ \\
Molten aluminum height & $0.60 \mathrm{~m}$ \\
Impeller height & $0.74 \mathrm{~m}$ \\
Impeller diameter & $0.05 \mathrm{~m}$ \\
Impeller head diameter & $0.18 \mathrm{~m}$ \\
Number of nozzles & 6 \\
Nozzle diameter & $0.01 \mathrm{~m}$
\end{tabular}


Table 2. Properties of the considered phases [15] [16].

\begin{tabular}{ccc}
\hline PROPERTY & MOLTEN ALUMINUM & NITROGEN \\
\hline Density, $\mathrm{kg} / \mathrm{m}^{3}$ & 2300 & 1.138 \\
Viscosity, $\mathrm{kg} /(\mathrm{m} \cdot \mathrm{s})$ & 0.0029 & $1.663 \times 10^{-5}$ \\
Surface tension, $\mathrm{N} / \mathrm{m}$ & 0.90 & --- \\
Temperature, ${ }^{\circ} \mathrm{K}$ & 973 & 298 \\
\hline
\end{tabular}

\section{Basic Fluid Mechanics}

Obtaining the proper diameter of nitrogen bubbles, their number and rise velocity is essential to get an efficient degassing of molten aluminum. The diameter of gas bubbles in the molten metal increases from an initial detachment value to a final value when the bubble leaves the metal bath [17]. The growth of the bubble diameter is explained by the thermal expansion of the gas in the molten aluminum, the decrease in the metalostatic pressure as the bubble ascends, and the coalescence phenomenon between bubbles. Of course, some breakage phenomenon may occur which contributes to reduce in some degree the bubble diameter.

Buoyancy and drag forces govern the rise velocity of bubbles in a liquid column. These forces are strongly dependent on the fluid properties and gravity [18]. Rise velocity determines the mean residence time of the bubbles inside the molten metal, and in turn, mean residence time affects the degassing rate. For injection of gases in molten metals at low gas flow rates, a balance between surface tension and buoyancy forces gives the following relationship to determine the bubble diameter [19]:

$$
d_{b}=\left[\frac{6 d_{n} \sigma}{g\left(\rho_{m}-\rho_{g}\right)}\right]^{1 / 3}
$$

where $d_{b}$ is the bubble diameter $(\mathrm{m}), d_{n}$ is the nozzle diameter $(\mathrm{m}), \sigma$ is the surface tension of the molten metal $(\mathrm{N} / \mathrm{m}), g$ is the gravity acceleration $\left(\mathrm{m} / \mathrm{s}^{2}\right), \rho_{m}$ is the density of the molten metal $\left(\mathrm{kg} / \mathrm{m}^{3}\right)$, and $\rho_{g}$ is the density of the gas $\left(\mathrm{kg} / \mathrm{m}^{3}\right)$.

For a single bubble, which almost spherical shape due to surface tension, Stokes's law is employed to determine the rise velocity [18]:

$$
v_{b}=\frac{g\left(\rho_{m}-\rho_{g}\right) d_{b}^{2}}{18 \mu_{m}}
$$

where $v_{b}$ is the rise velocity of the bubble $(\mathrm{m} / \mathrm{s})$, and $\mu_{m}$ is the viscosity of the molten metal $(\mathrm{kg} / \mathrm{m} \cdot \mathrm{s})$.

In absence of rotation of the impeller and for slender degassing tanks, the bubbles travel an approximate linear path from the point of detachment to the molten metal surface. Then, the mean residence time can be estimated from the relationship [20]

$$
\tau_{r}=\frac{H}{v_{b}}
$$


where $\tau_{r}$ is the mean residence time (s), and $H$ is the impeller immersion depth (m).

Degassing and homogenization of molten metal temperature and composition by gas bubbling is primarily caused by the dissipation of the buoyant energy of the injected gas. The stirring power of the molten metal is estimated here from a modified version of the Pluschkell's relationship [21]:

$$
\dot{\varepsilon}=14.23\left(\frac{Q T}{60 W}\right) \ln \left(\frac{1+H}{1.48 P_{0}}\right)
$$

where $\dot{\varepsilon}$ is the stirring power of the melt (W/ton), $Q$ is the gas flowrate $\left(\mathrm{m}^{3} / \mathrm{h}\right)$, $T$ is the melt temperature $\left({ }^{\circ} \mathrm{K}\right), W$ is the melt weight $(\mathrm{kg})$, and $P_{0}$ is the gas pressure at the melt surface (atm).

In [21], the mixing time is defined as the time required for achieving $95 \%$ of thermal and chemical homogenization in the melt. The mixing time can obtained from the expression [22]:

$$
\tau_{m}=116(\dot{\varepsilon})^{-1 / 3} D^{5 / 3} H^{-1}
$$

where $\tau_{m}$ is the mixing time (s), and $D$ is the diameter of the degasser tank (m).

On the other hand, transient 2D CFD simulations were carried out to elucidate the influence of the nitrogen volumetric flow rate on the phase distributions and the tank degasser dynamics. The conservation of momentum and mass of the molten aluminum and nitrogen was modeled using the Navier-Stokes and the continuity equations [23], respectively. The classical K- $\varepsilon$ model was selected to simulate turbulence [24]. To represent the multiphase flow, the Volume of Fluid (VOF) model [25] was employed. Finally, the Pressure Implicit with Splitting Operations (PISO) algorithm was selected for the pressure-velocity coupling [16].

\section{Results and Comments}

Figure 2 shows the influence of the nozzle diameter on the diameter of nitrogen bubbles in the molten aluminum. As the nozzle diameter is increased, the bubble diameter increases too. The bubble diameter corresponding to the nozzle diameter of Table 1 is $0.0134 \mathrm{~m}$. Bubble sizes in the range of 0.003 to $0.010 \mathrm{~m}$ in diameter are recommended to solve the problems of insufficient gas distribution and poor homogenization [26]. Figure 2 also shows that the mean residence time of bubbles decreases as the nozzle diameter is increased. For a nozzle diameter of Table 1 the mean residence time is $0.0071 \mathrm{~s}$. In [20] there are reported rise velocities of bubbles the range of 0.21 and $0.32 \mathrm{~m} / \mathrm{s}$ for bubble diameters from 0.004 to $0.0165 \mathrm{~m}$ in molten metals such as tin, lead and copper. For molten aluminum, the reported rise velocities go from 0.35 to $0.45 \mathrm{~m} / \mathrm{s}$, with only slight influence of the bubble size [27]. In accordance to Stokes's law of Equation (2), the rise velocity of a nitrogen bubble of $0.0134 \mathrm{~m}$ in molten aluminum (which corresponds to the nozzle diameter of Table 1), is $77.57 \mathrm{~m} / \mathrm{s}$. This means that the Stokes's law clearly overestimates the rise velocity of nitrogen bubbles, 


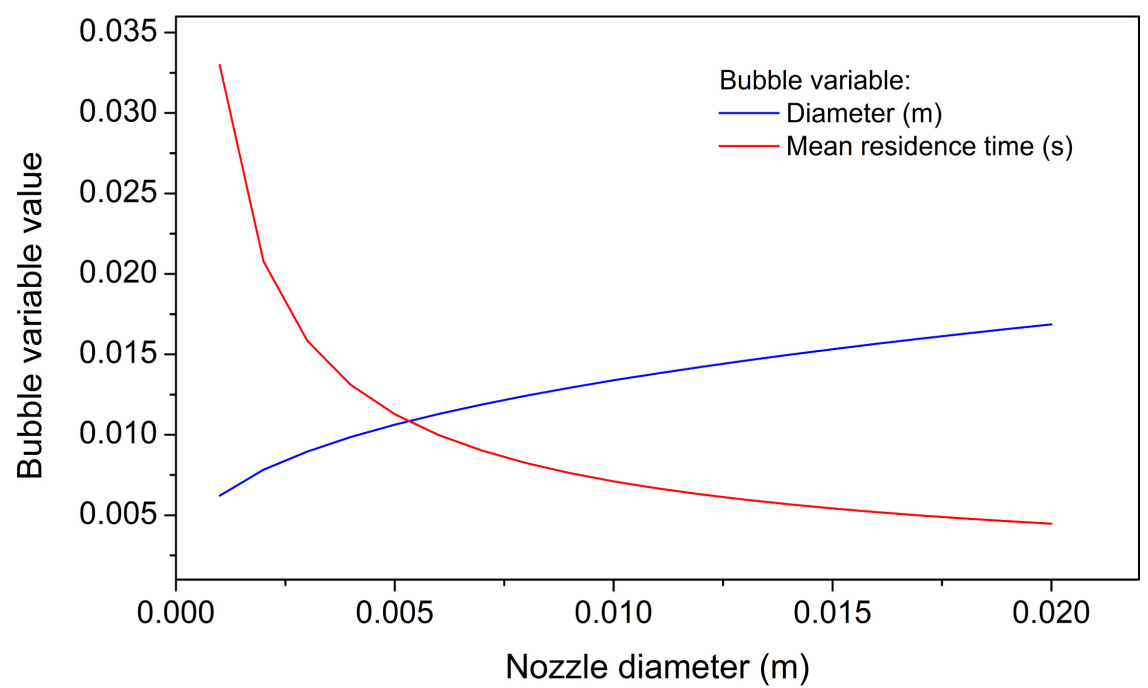

Figure 2. Diameter and mean residence time of nitrogen bubbles as function of the nozzle diameter.

and therefore underestimate their mean residence time. However, at least qualitatively, Figure 2 represents properly the influence of the nozzle diameter on the rise velocity and the residence time of nitrogen bubbles in molten aluminum.

Figure 3 shows the influence of the nitrogen volumetric flow rate on the stirring power of molten aluminum determined from Equation (4) and using the data of Table 1. As expected by observing Equation (4), Figure 3 exhibits a linear dependence between the aforementioned variables. This means that the mean velocity, the kinetic energy and the turbulence of the molten aluminum in linearly increased when the nitrogen flow rate is increased. On the contrary, Figure 4 presents a nonlinear decreasing dependence between nitrogen flow rate and mixing time. This nonlinear dependence is explained by Equation (5), which exhibits a nonlinear pattern between the stirring power and the mixing time. For low values of the nitrogen flow rate, the mixing times decreases rapidly as the flow rate is increased, however for values of the flow rate above of $3 \mathrm{~m}^{3} / \mathrm{h}$, the decreasing of the mixing time is slower.

Results of the CFD transient isothermal 2D simulations show the evolution of the phase distributions in the tank degasser, and these results are depicted in Figures 5-7 for values of the nitrogen flow rate of $1,1.5$ and $2 \mathrm{~m}^{3} / \mathrm{h}$, respectively. A $0.0001 \mathrm{~s}$ of time step was employed to guarantee numerical stability, and just two nozzles were considered in the computer experiments. Bubble penetration and rise in the molten aluminum increases as time elapses, as is appreciated in these figures. Besides, it can be noted that the nitrogen flow rates accelerates the tank degasser dynamics, i.e. the time required to achieve the same level of stirring in the melt decreases as the nitrogen flow rate is increased. In Figure 8 are depicted the phase distribution and the flow lines in the tank degasser after $1 \mathrm{~s}$ for a nitrogen flow rate of $3 \mathrm{~m}^{3} / \mathrm{h}$. Flow lines of Figure $8(\mathrm{~b})$ indicate that for this flow rate even the bottom of the tank is well agitated. 


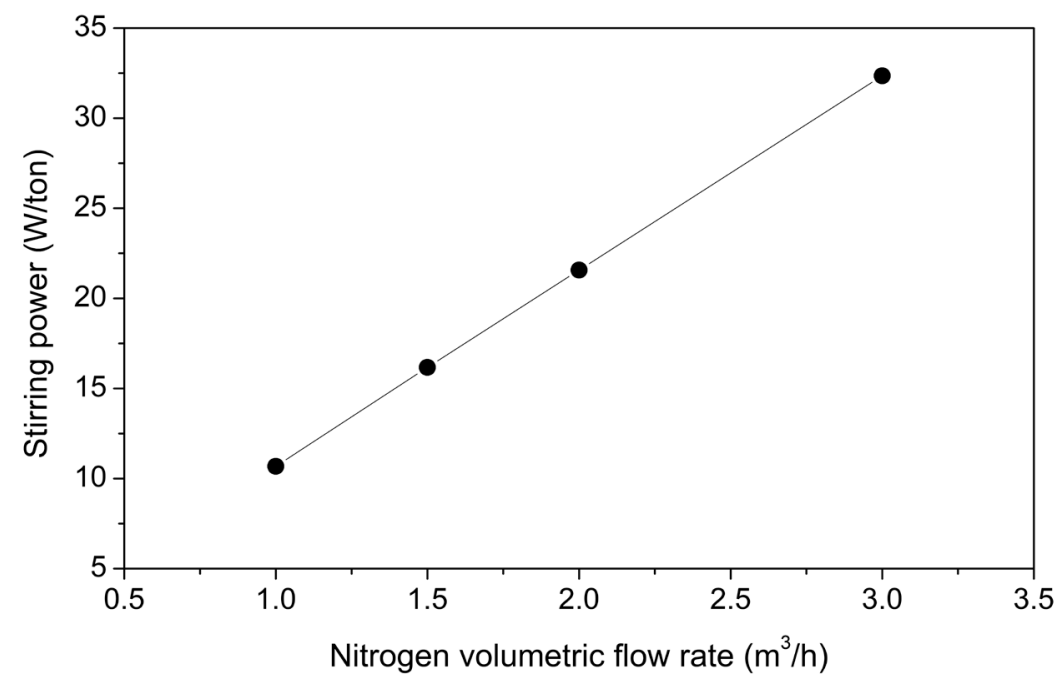

Figure 3. Stirring power of molten aluminum as function of the volumetric flow rate of nitrogen.

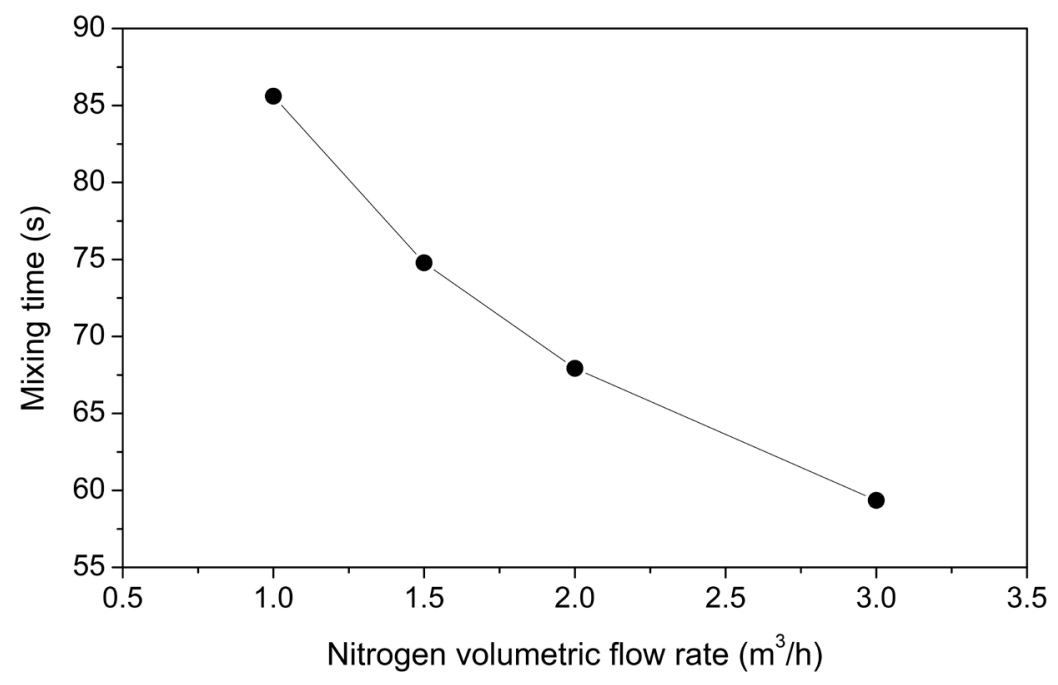

Figure 4. Mixing time of molten aluminum as function of the volumetric flow rate of nitrogen.

A non-isothermal CFD simulation was carried out under adiabatic conditions for a nitrogen flow rate of $3 \mathrm{~m}^{3} / \mathrm{h}$. Simulation was stopped once a global mass balance detected spitting of molten aluminum. Figure 9 shows the temperature distribution in molten aluminum and nitrogen. Temperature in both phases remains practically equal in all regions of the tank degasser at the initial temperature of molten aluminum $\left(973{ }^{\circ} \mathrm{K}\right)$, except in the vicinity of the inlet nozzles of the impeller, where the nitrogen is fed at a temperature of $298{ }^{\circ} \mathrm{K}$. Molten aluminum does not suffer drastic temperature reductions given that, in spite the nitrogen is fed at ambient temperature, the mass of nitrogen is relatively small compared with the mass of aluminum. On the contrary, the small mass of nitrogen is easily heated to the aluminum temperature as it ascends to the melt surface. 


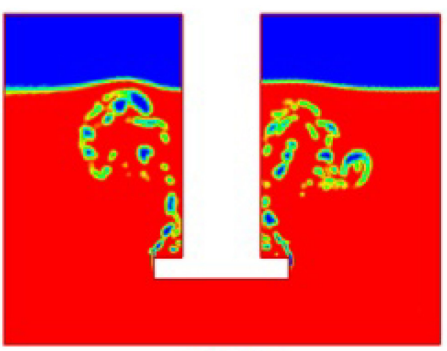

(a) $1 \mathrm{~s}$

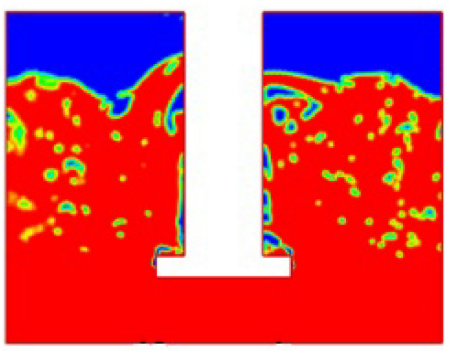

(c) $10 \mathrm{~s}$

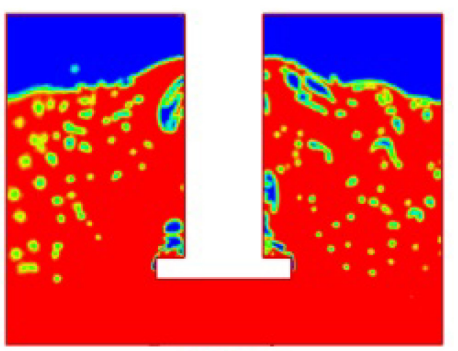

(b) $5 \mathrm{~s}$

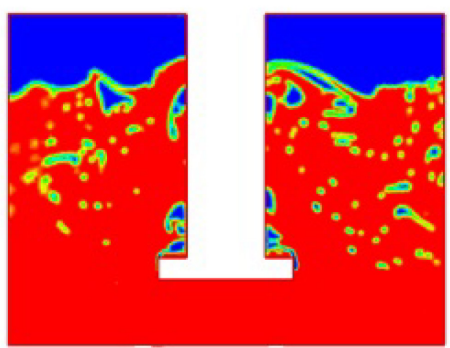

(d) $15 \mathrm{~s}$

Figure 5. Phase distribution in the tank degasser for a nitrogen flow rate of $1 \mathrm{~m}^{3} / \mathrm{h}$ under isothermal conditions. Red phase is molten aluminum, blue phase is nitrogen.

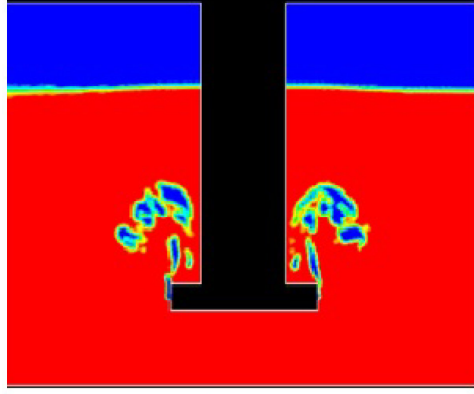

(a) $0.5 \mathrm{~s}$

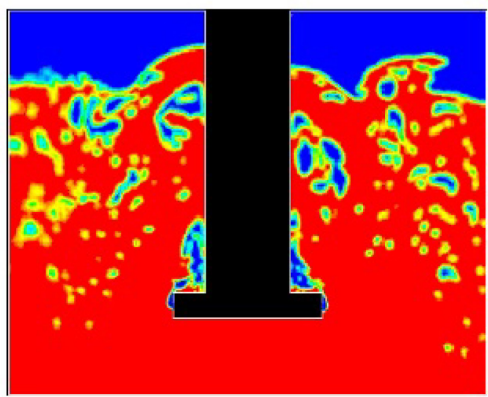

(c) $3 \mathrm{~s}$

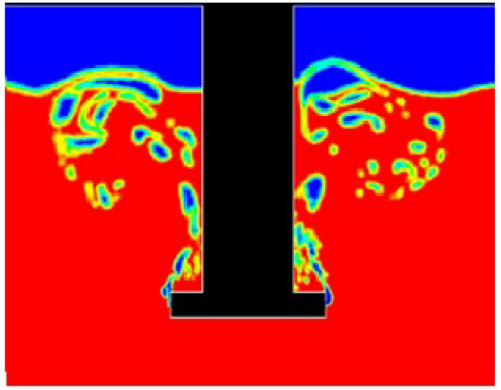

(b) $1 \mathrm{~s}$

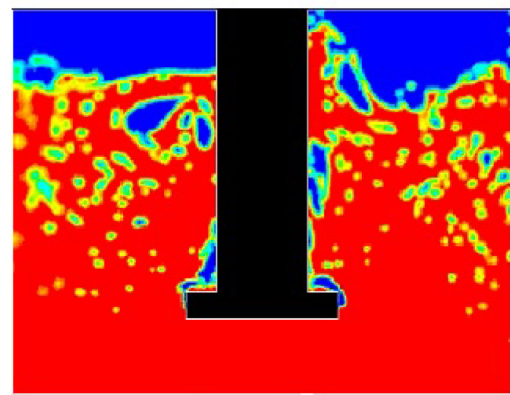

(d) $4 \mathrm{~s}$

Figure 6. Phase distribution in the tank degasser for a nitrogen flow rate of $1.5 \mathrm{~m}^{3} / \mathrm{h}$ under isothermal conditions.

\section{Conclusions}

The injection of nitrogen in molten aluminum in an industrial-like tank degasser with a static impeller was studied. From a basic fluid mechanics analysis and 


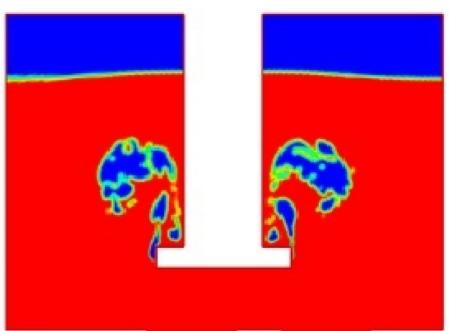

(a) $0.5 \mathrm{~s}$

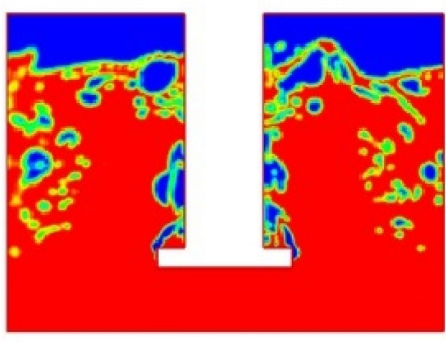

(c) $1.5 \mathrm{~s}$

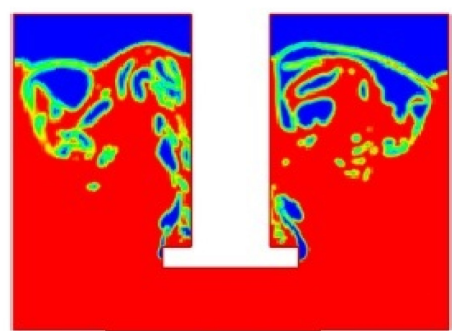

(b) $1 \mathrm{~s}$

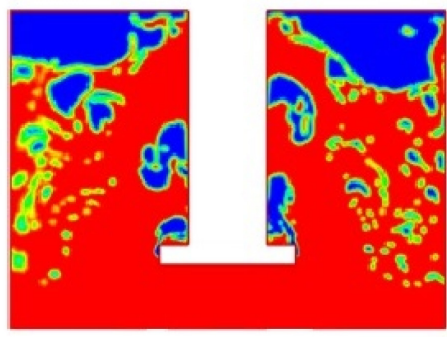

(d) $2 \mathrm{~s}$

Figure 7. Phase distribution in the tank degasser for a nitrogen flow rate of $2 \mathrm{~m}^{3} / \mathrm{h}$ under isothermal conditions.

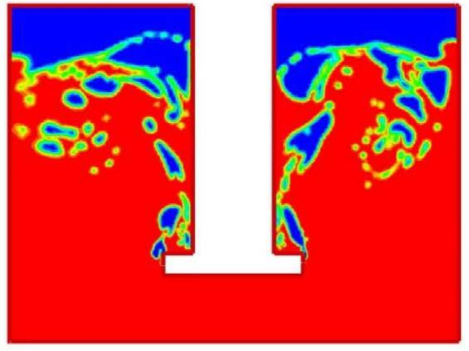

(a)

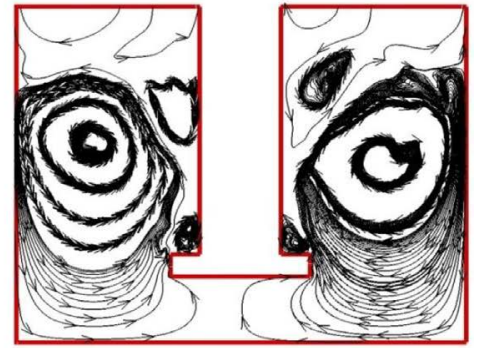

(b)

Figure 8. Phase distribution and flow lines in the tank degasser for a nitrogen flow rate of $3 \mathrm{~m}^{3} / \mathrm{h}$ under isothermal conditions after $1 \mathrm{~s}$.

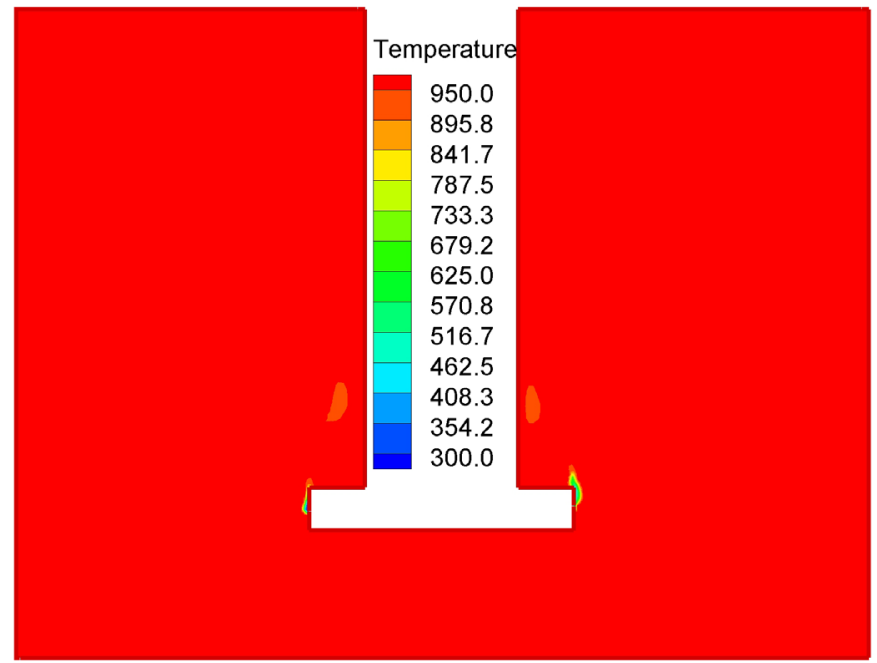

Figure 9. Temperature distribution under adiabatic conditions in the tank degasser for a nitrogen flow rate of $3 \mathrm{~m}^{3} / \mathrm{hr}$. 
Computational Fluid Dynamics simulations, the following conclusions are established:

1) In absence of rotation of the impeller, the value of the diameter of the impeller nozzles is very important given that it determines the nitrogen bubble diameter, and hence the rise velocity and the mean residence time of this bubble.

2) The nitrogen volumetric flow rate affects in a non-linear decreasing pattern the mixing time of molten aluminum.

3) As the nitrogen volumetric flow rate is increased, the dynamics of the tank degasser becomes faster. This means that less time is required to achieve the desired degree of stirring.

4) Temperature of molten aluminum is slightly affected by the presence of nitrogen in the melt, in spite that the nitrogen is injected at ambient temperature.

\section{Conflicts of Interest}

The authors declare no conflicts of interest regarding the publication of this paper.

\section{References}

[1] Kucharcik, L., Bruna, M. and Sladek, A. (2014) Influence of Chemical Composition on Porosity in Aluminium Alloys. Archives of Foundry Engineering, 14, 5-8. https://doi.org/10.2478/afe-2014-0026

[2] Utigard, T.A., Friesen, K., Roy, R.R., Lim, J., Silny, A. and Dupuis, C. (1998) The Properties and Uses of Fluxes in Molten Aluminum Processing. Journal of Metals, 50, 38-43. https://doi.org/10.1007/s11837-998-0285-7

[3] Saravanakumar, P., Bhoopashram, J., Kavin Prasath, M. and Jaycharan, M. (2017) Role of Salt Fluxes in Aluminium Refining: A Review. International Journal of Latest Engineering and Management Research, 2, 45-51.

[4] Totten, G.E. and Scott Mackenzie, D. (2003) Handbook of Aluminum. Marcel Dekker Inc., New York, NY.

[5] Popescu, G., Gheorghe, I., Danila, F. and Moldovan, P. (1996) Vacuum Degassing of Aluminium Alloys. Materials Science Forum, 217-222, 147-152. https://doi.org/10.4028/www.scientific.net/MSF.217-222.147

[6] Zeng, J., Wu, B., Hu, Z., Wang, L. and Cao, D. (2014) A New Vacuum Degassing Process for Molten Aluminum. In: Grandfield, J., Ed., Light Metals 2014, Springer, Cham, 1051-1054.

[7] Alba-Baena, N. and Eskin, D. (2013) Kinetic of Ultrasonic Degassing of Aluminum Alloys. In: Sadler, B.A., Ed., Light Metals 2013, Springer, Berlin, 957-962. https://doi.org/10.1002/9781118663189.ch162

[8] Puga, H., Barbosa, J., Tuan, N.Q. and Silva, F. (2014) Effect of Ultrasonic Degassing on Performance of Al-Based Components. Transactions of Nonferrous Metal Society of China, 24, 3459-3464. https://doi.org/10.1016/S1003-6326(14)63489-0

[9] Han, Q. (2014) Ultrasonic Degassing of Aluminum Alloys. Materials Science Forum, 783-786, 155-160. https://doi.org/10.4028/www.scientific.net/MSF.783-786.155

[10] Liping, W., Guojian, C., Erjun, G., Guojun, W. and Xinyu, L. (2013) Influences of Different Degassing Processes on Refining Effect and Properties of 4004 Al Alloy. China Foundry Research and Development, 10, 104-107. 
[11] Mancilla, E., Cruz-Mendez, W., Garduño, I.E., Gonzalez-Rivera, C., Ramirez-Argaez, M.A. and Ascanio, G. (2017) Comparison of the Hydrodynamic Performance of Rotor-Injector Devices in a Water Physical Model of an Aluminum Degassing Ladle. Chemical Engineering Research and Design, 118, 158-169. https://doi.org/10.1016/j.cherd.2016.11.031

[12] Ramos-Gomez, E., Zenit, R., Gonzalez-Rivera, C., Trapaga, G. and Ramirez-Argaez, M.A. (2013) Mathematical Modeling of Fluid Flow in a Water Physical Model of an Aluminum Degassing Ladle Equipped with an Impeller-Injector. Metallurgical and Materials Transactions B, 44, 423-435. https://doi.org/10.1007/s11663-012-9774-8

[13] Abreu-Lopez, D., Amaro-Villeda, A., Acosta-Gonzalez, F., Gonzalez-Rivera, C. and Ramirez-Argaez, M.A. (2017) Effect of the Impeller Design on Degasification Kinetics Using the Impeller Injector Technique Assisted by Mathematical Modeling. Metals, 7, 132.

[14] Mostafaei, M., Ghobadi, M., Eisaabadi, G., Uludag, M. and Tiryakioglu, M. (2016) Evaluation of the Effects of Rotary Degassing Process Variables on the Quality of A357 Aluminum Alloy Castings. Metallurgical and Materials Transactions B, 47, 3469-3475. https://doi.org/10.1007/s11663-016-0786-7

[15] Kauffman, J.G. (2016) Fire Resistance of Aluminum and Aluminum Alloys, Chapter 1. ASM International, Materials Park, $\mathrm{OH}$.

[16] (2003) Fluent 6.1 User's Guide.

[17] Pieprzyca, J., Kudlinski, Z., Michalek, K., Gryc, K. and Tkadleckova, M. (2012) Modelling Steel's Homogenization during Argon Purging. Journal of Achievements in Materials and Manufacturing Engineering, 55, 573-577.

[18] Talaia, M.A.R. (2007) Terminal Velocity of a Bubble Rise in a Liquid Column. International Journal of Physical and Mathematical Sciences, 14, 220-224.

[19] Szekely, J. (1979) Fluid Flow Phenomena in Metals Processing. Academic Press, New York.

[20] Andreini, R.J., Foster, J.S. and Callen, R.W. (1977) Characterization of Gas Bubbles Injected into Molten Metals under Laminar Flow Conditions. Metallurgical Transactions B, 8, 625-631. https://doi.org/10.1007/BF02669340

[21] Fruehan, R.J. (1998) The Making, Shaping and Treating of Steel. Steelmaking and Refining Volume. The AISE Steel Foundation, Pittsburgh.

[22] Mazumdar, D. and Guthrie, R.I.L. (1986) Mixing Models for Gas Stirred Metallurgical Reactors. Metallurgical Transactions B, 17, 725-733. https://doi.org/10.1007/BF02657134

[23] Bird, R.B., Stewart, W.E. and Lightfoot, E.N. (2002) Transport Phenomena. 2nd Edition, Wiley, New York.

[24] Thomas, B.G., Yuan, Q., Sivaramakrishnan, S., Shi, T., Vanka, S.P. and Assar, M.B. (2001) Comparison of Four Methods to Evaluate Fluid Velocities in a Continuous Slab Casting Mold. ISIJ International, 41, 1262-1271. https://doi.org/10.2355/isijinternational.41.1262

[25] Hirt, C.W. and Nichols, B.D. (1981) Volume of Fluid (VOF) Method for the Dynamics of Free Boundaries. Journal of Computational Physics, 39, 201-225. https://doi.org/10.1016/0021-9991(81)90145-5

[26] http://www.foundry-planet.com/fileadmin/redakteur/pdf-dateien/technical-reports/ 12-12-11-Foseco_batch\%20degassing\%20for\%20aluminium\%20melts.pdf

[27] Grandfield, J.F. and Eskin, D.G. (2016) Essential Readings in Light Metals. Volume 3, Springer, Berlin. https://doi.org/10.1007/978-3-319-48228-6 